\title{
Diálogos interdisciplinares para uma agenda socioambiental: breve inventário do debate sobre ciência, sociedade e natureza
}

\author{
Dimas FLORIANI* \\ “...la ficción es la construcción de ciertos fragmentos que se apoyan en \\ momentos vividos y les dan forma. Lo que se escribe tiene una intensidad \\ y una presencia que no se superponen con la vida, que tiene construída su \\ propria memoria”.
}

(RICARDO PIGLIA)

\section{RESUMO}

\begin{abstract}
O debate sobre ciência, sociedade e natureza, na perspectiva da construção de um novo conhecimento interdisciplinar, exige uma reflexão crítica sobre os fundamentos da racionalidade científica moderna. Por outro lado, a crítica que se faz ao conhecimento científico, coincide com a crítica ao fracionamento que se faz entre sociedade e natureza, com todas as suas implicações sócio-culturais e políticas. Razão instrumental e sistema de crenças andam juntos. Daí que uma crítica profunda sobre a racionalidade e as práticas científicas, no âmbito da relação sociedade-natureza, deve buscar reaproximar os saberes disciplinares, principalmente os das ciências da vida, da natureza e da sociedade. Esse diálogo entre saberes científicos não pode, entretanto, excluir as outras formas de conhecimento do mundo, da natureza e das sociedades.
\end{abstract}

Palavras-chave: Natureza e Sociedade, Interdisciplinaridade, Racionalidade Científica

\begin{abstract}
The debate on science, nature and society, from the perspective of the construction of a new interdisciplinary knowledge, requires critical refelctions on the bases of modern scientific rationality. On the other hand, the critique of scientific knowledge that has been made coincides with the critique of the division between society and nature, with all of its socio-cultural and political implications. Instrumental reason and belief system develop together.

Therefore, a deep critique of rationality and scientific practices, from the perspective of the societynature relationship, should seek to bring the knowledge that has been separated into different disciplines closer together again, especially with regard to the life sciences, that is, those of nature and society. This dialogue between fields of scientific knowledge should not, at the same time, exclude other forms of knowing the world, nature and society.
\end{abstract}

Key-words: Nature and society, Interdisciplinarity, Scientific rationality

\footnotetext{
* Doutor em Sociologia, Professor Titular do Departamento de Ciências Sociais (Graduação e Mestrado) e do Doutorado em Meio Ambiente e Desenvolvimento da UFPR. E-mail: dimas@ reitoria.ufpr.br
} 


\section{Apresentação}

Conforme ao que se pensa, se faz; de acordo com que se faz, se pensa. Essa ação pendular e dialógica está presente no fazer social e humano. O conhecimento científico é uma forma de pensar e de fazer ${ }^{1}$. Tem-se pensado, ao longo da história das sociedades, com racionalidades distintas. Sabe-se, em um sentido aproximado, como as sociedade produtivistas concebem seus planos para melhor instrumentalizar o mundo material (da mesma maneira que o simbólico). Pode-se afirmar que o modelo produtivista de sociedade - que concebe a produção e o consumo como um fim em si - tende a internalizar a entropia, pois concebe a transformação e o consumo da matéria como algo em si e de maneira ilimitada: a contingênica transforma-se em necessidade e a necessidade em contingência; o supérfluo toma o lugar da necessidade e vice-versa. A alienação na forma de produção do mundo produz uma alienação na forma de apropriação e distribuição da riqueza, além de afunilar as expectativas humanas e sociais para a produção do desejo de ter. Ter é ser. A falha no ser é não poder ter, uma vez que o sistema de produção de mercado distribui a riqueza social de forma desigual. Passa-se a desejar o que ainda não é, o que pode ser, mas também o que deve ser (uma compulsão ao desejo fetichizado).

O desafio da ciência é o da própria sociedade. Como visar objetivos que a sociedade vislumbra, mesmo sem muita clareza ainda, levando em conta a multiplicidade de interesses, de concepções, de práticas e de resultados alcançados e a alcançar? Existe uma engenharia, uma arquitetura, uma estética, uma economia, uma política capazes de combinar essa complexa diferença transformando desejos em realidade? O único acordo, embora provisório e instável, é de que o modelo de expropriação da natureza, feito nos moldes dominantes, não pode perdurar indefinidamente, sob pena de inviabilizar a vida na Terra.

Assim sendo, como mudar mentalidades e, mais do que isto, práticas consolidadas de produção e repro- dução do conhecimento e das condições de vida, em suas mais variadas formas? Como revisar ou subverter as premissas que sustentam as concepções de ciência e de sociedade? Como buscar novos consórcios, parcerias ou contratos sociais que integrem a pluralidade de visões, garantindo a autonomia dos projetos culturais, e sejam capazes de compreender a relação sociedade-natureza em bases novas, criando outras condições de sociabilidade em escala local e planetária? Como conciliar razão universal que assegura, no domínio da política, direitos para todos, com a pluralidade de identidades, isto é, de subjetividades diversas? Ou seja, esse difícil equilíbrio entre racionalidade e liberdade de ser, discutido por Alain Touraine (1994).

Enquanto produção de linguagem, a ciência parece utilizar-se de recursos não apenas lógicos mas também extra-lógicos (metafísicos às vezes, estéticos outras). Neste sentido, parafraseando o escritor argentino Ricardo Piglia (2000), quando se referia ao papel da ficção literária, podemos afirmar que o conhecimento científico se apóia em experiências e construções teóricas, mas nem sempre se superpõe à vida, já que esta possui sua própria memória, refratária, em muitos casos àquela discursividade. Se a linguagem da ciência se distanciou de outras formas de simbolização da realidade, não significa, entretanto, que sejam antagônicas em suas representações. Ao longo do texto, pretendemos, por sinal, apontar para os "desvios" de percurso dessas linguagens. Poderia ser um equívoco separá-las umas das outras, em que pese suas especificidades simbólicas e seus campos de representação da realidade não serem concorrentes.

Feyerabend (1991), por sua vez, vê na metafísica não apenas aspectos positivos, pois permite especular além da instrumentalidade da ciência, mas também negativos, dado o sistema de valores sobre os quais uma sociedade tende a legitimar o uso científico. A estética juntamente com outras expressões do conhecimento (religioso, tradicional, espontâneo, etc.) podem ser, então, para muitos cientistas e filósofos da ciência (Bohm; Peat,

1 Rogério Parentoni Martins, biólogo da UFMG, a quem devo agradecimentos pela leitura e comentários críticos a meu texto, sustenta que " $o$ conhecimento científico não é uma forma de pensar e fazer, mas o resultado do pensar e fazer". Aproveitando seu comentário, diria que ambas características são complementares. Forma ou estrutura lógico-discursiva, bem como resultado são constitutivos do 'processo científico', cuja validação não é apenas instrumental mas também cultural. 
1989; Prigogine, 1996), aliadas estratégicas contra a visão cientificista e instrumentalizadora do real, que visa principalmente objetivos tecnológicos ${ }^{2}$.

Existe ou não a possibilidade de se constituir um campo único (mais do que isto, unificado) sobre o universo, a vida, a natureza, a sociedade? As indicações captadas até o presente parecem não confirmar essa possibilidade. A teologia, a filosofia monista, o pensamento oriental, africano, indígena ocidental e outras formas mitológicas de representação do mundo procediam à elaboração de uma cosmologia e de uma teogonia envolvendo a natureza, a sociedade e o destino humano (este, captado pelas religiões). Essa discussão, longe de acabar, encontra no interior do pensamento científico moderno um campo propício para confrontos bastante acalorados, sobre a fragmentação do conhecimento, a hiperespecialização das ciências, a ruptura entre natureza e sociedade, entre o objetivo e o subjetivo, o individual e o coletivo, etc.

Como enfrentar esse debate no interior da problemática do meio ambiente e do desenvolvimento sustentável?

Entender os processos constitutivos do conhecimento científico modernos exige indagações sobre: 1) os pressupostos epistemológicos (o que é o conhecimento científico e de onde este procede, a que fontes filosóficas e cognitivas responde); 2) os procedimentos metodológicos ligados aos "objetos de conhecimento" (entre aspas, pois a idéia de objeto está associada a um determinado valor e cultura científica) e 3) uma relação mais geral do binômio sujeito-objeto. A crítica que é feita hoje sobre a lógica dominante do conhecimento científico está associada a projetos de elaboração de conhecimentos alternativos, ora incitando ao diálogo de saberes (Leff, 1999) ora filiando-se a concepções holísticas do mundo (Capra, 1992).

Realidade, verdade e certeza no interior das civilizações técnicas são determinadas pelos códigos científicos; estes códigos, por sua vez, criam outros signos de verdade, de realidade e de (in)certezas (Morin, 1991), ao longo do processo de produção do conhecimento científico. A dialética dessas certezas e ambigüidades, quando se conecta com os circuitos sociais, é definida em termos de reflexividade ou de modernização reflexiva (Giddens, 1989; 1991; 1997).

A construção do conhecimento científico não pode ser entendida apenas como uma conquista de procedimentos rigorosos e perfeitamente controláveis. Entendêlos assim, como insuspeitos e exclusivos, cumulativos e lineares, constitui uma ideologia de ciência. Se uma determinada época elege certos procedimentos consagrados de descoberta científica em detrimento de outros, significa não apenas uma maior eficácia na produção de verdades e de resultados, mas também um maior consenso e legitimidade adquiridos no interior das comunidades científicas. Quando aplicado às ciências sociais, onde os conceitos de verdade, de experimentação e de controle são mais vulneráveis do que nas outras ciências da natureza, este argumento torna-se parcialmente insustentável.

Um dos principais objetivos deste artigo é abordar transversalmente algumas dessas temáticas aqui apresentadas. Abordá-las na perspectiva não apenas especulativa, mas aplicada ao contexto do programa de pesquisa interdisciplinar, em andamento no Doutorado em Meio Ambiente e Desenvolvimento da UFPR, onde se conjugam atividades de pesquisa e de ensino-formação. Construir o conhecimento de maneira interdisciplinar, nas interfaces dos sistemas natural e social não se dá em um passe de mágica, nem por boas intenções teóricas. Neste sentido, a produção do conhecimento interdisciplinar é um processo em construção, onde as barreiras bem plantadas de uma cultura científica departamental e disciplinar representam apenas o seu lado mais aparente. O caminho para as mudanças será certamente longo para todos aqueles que se lançam em semelhante aventura. A prudência neste caso não é recomendável, pois ela mantém as coisas como estão, embora possa poupar-nos do desgaste da ousadia e das incertezas dos resultados esperados.

2 Não pretendemos aqui comparar ciência e religião. Chama porém atenção a força da analogia entre ambas, já que mobilizam crenças, práticas ritualísticas e institucionais; ambas tiveram e têm suas respectivas primazias ao longo do tempo nas sociedades humanas; ambas desenvolvem suas cosmovisões em relação à natureza e às expectativas humanas. O campo científico é tão ou mais controverso do que o campo religioso. 


\section{Ciência e sociedade: práticas e representações}

Compreender a natureza foi um dos grandes projetos do pensamento ocidental. Ele não deve ser identificado com o de controlar a natureza. Seria cego o senhor que acreditasse compreender seus escravos sob pretexto de que eles obedecem às suas ordens (Ilya Prigogine, 1996, p. 157).

As ações humanas, por estarem inseridas em contextos históricos e culturais e independentemente do que se propõem e a que resultados alcancem, são portadoras de sentidos que influenciam as suas próprias orientações. Isto é visível na economia, na religião, na política, na ciência, na estética e nas demais esferas sociais. Nem sempre o que é visado pelo coletivo e pelos indivíduos sociais torna-se de imediato consciente ou transparente para eles. Daí o permanente conflito entre as possibilidades de ação e as escolhas assumidas: os interesses sobrepõem-se uns aos outros ao ganharem conteúdos e formas de expressão concretos ${ }^{3}$. Muito embora o significado histórico das atividades humanas possa ser representado como algo fora do controle dos indivíduos, está ao alcance destes entender aquelas atividades, criticá-las e até superá-las. Só não está demonstrado na evolução das sociedades, porquê se toma esse ou aquele rumo. A história das ciências parece demonstrar bem esse movimento, representado por grandes embates, alguns dos quais cruentos. A concepção marxista de sociedade vincula a história do progresso técnico, com as mudanças materiais e espirituais (ideológicas) das distintas etapas da evolução social. Para Marx, o moinho a vapor prenuncia a sociedade industrial, contrariamente ao moinho de água associado ao modo de produção anterior. Ambas formas condicionam os agentes sociais que as protagonizam (senhores e servos, por um lado e burgueses e proletários, por outro). O trabalho se organiza e se divide de diferentes formas, segundo os instrumentos de produção disponíveis (Marx, 1973, p. 90).

No interior das modernas atividades do conhecimento institucional, representadas pela produção, dis- tribuição e consumo da ciência e da técnica, em escala nacional e internacional, o conhecimento científico é um campo de disputas materiais e simbólicas, onde ocorrem conflitos das mais diversas ordens: econômicos (associados a inovações tecnológicas e aos mercados), políticos (disputas de hegemonia, poder e prestígio das instituições e entre pesquisadores) filosóficos (debates acirrados sobre concepcões teórico-metodológicas, natureza e finalidade das ciências, etc.) e culturais (maneiras de apropriação e de representação da natureza e transformação da matéria - simbolização que devolve aos homens crenças e rejeições sobre sua cosmovisão).

Do ponto de vista do debate epistemológico, a contemporaneidade - entendida pela temporalidade recente do século XX e de seu próximo limiar - elegeu uma série de debates teóricos que expressam tanto a crise das concepções de ciência, como as alternativas que se desenham nos novos horizontes paradigmáticos possíveis. Como a produção da ciência se insere no contexto cultural das sociedades, ela também é uma de suas expressões. Neste sentido, se couber atribuir especificidades à modernidade, é que esta não se caracteriza por uma dimensão ou outra, mas pela combinação e pela simultaneidade de processos econômicos, científico-tecnológicos, ambientais, políticos, comunicacionais, informacionais, culturais, étnicos, religiosos e outros mais, compondo uma espécie de holograma. Se a modernidade puder ser definida, um de seus conteúdos é a multiplicidade de situações, a originalidade de manifestações culturais e a afirmação de identidades sócio-culturais múltiplas, em que pese uma aparente unidade induzida pelo processo de globalização.

Uma das principais críticas dirigidas ao atual processo de produção do conhecimento científico deriva de sua hiper-especialização (leia-se fragmentação), trazendo graves consequiências para o entendimento e a explicação da realidade, principalmente no domínio das ciências da vida, da natureza e também da sociedade; como as sociedades modernas estão apoiadas em bases produtivistas, ao conhecimento científico é imposta uma racionalidade instrumental, traduzindo-se em técnica intervencionista, tanto na natureza como na sociedade

3 "As decisões humanas dependem das lembranças do passado e das expectativas para o futuro" (Prigogine, 2000, p. 5) 
(como diferenciar a sociedade da natureza, quando ocorre uma crescente artificialização da matéria, pela técnica, tornando-se a natureza uma espécie de matéria socializada?).

Mais recentemente, no quadro das transformações do Pós-Guerra (pós-1945), as sociedades industriais sofrem mutações tecnológicas e organizacionais, merecendo de alguns analistas novas designações (sociedades pós-industriais, programadas, complexas, do conhecimento e, mais recentemente, de capitalismo informacional) ${ }^{4}$. A produção do conhecimento por essas sociedades, tem mais a ver com a emergência de novas formas de cooperação das sociedades científicas (e a seus evidentes conflitos de poder), vinculadas ou subordinadas às demandas estratégicas das grandes corporações industriais (principalmente laboratórios) no desenvolvimento de novos produtos (biotecnologia, engenharia genética, micro-eletrônica, pesquisa de novos materiais, etc.).

As sociedades de sábios se multiplicam. No século XIX, a ciência se instala na universidade, através de departamentos e laboratórios. O termo Scientist aparece na Inglaterra em 1840, profissionalizando a ciência. Nem empresas nem aparelhos de Estado são poupados pela presença de profissionais da ciência (Morin, 1991, p. 57). Em 1980, a Unesco recenseou 2.600 pesquisadores por milhão de habitantes nos países industrialmente avançados e pouco mais de 100 nos outros. A França contava em 1992 com 26 mil pesquisadores ou técnicos; e o conjunto de todos os organismos de pesquisa atingia, em 1984, mais de 300 mil assalariados (Granger, 1994, p. 17).

Eis um bom exemplo, uma vez mais, da concentra- ção do know how em regiões que reforçam a desigualdade entre as nações. A desigualdade social pós-moderna, desapercebida de sua gênese e de seu contexto histórico ou, pior ainda, desassistida de qualquer mecanismo de correção ético-política, é a expressão da degradação da eqüidade social, comprometendo a idéia mesma de sustentabilidade. Somando-se outros fatores de desequilíbrio econômico, político e ambiental entre regiões e nações (domínio tecnológico, produção e consumo de energia, estilos de consumo, poluição do ar, controle dos mecanismos financeiros, etc.) obtém-se indicadores dos desequilíbrios existentes em escala global.

Ao autonomizar-se institucionalmente, a ciência cria também vínculos com o desenvolvimento econômico, técnico e social, integrando-se cada vez mais no planejamento técnico das sociedades e infiltrando-se capilarmente na racionalidade do sistema social moderno. Neste sentido, a ciência, enquanto sistema integrado de saberes, racionalidades e técnicas, pode ser representada em forma de holograma: ao incluir-se na sociedade, a ciência é simultaneamente o próprio continente social (conteúdo e continente). Daí, a sociedade perceber-se solidária (produtora e consumidora) com as formas cognitivas e práticas científicas dominantes.

\section{Conhecimento científico e realidade: algumas (in) certezas}

A possibilidade de se definir o que seja conhecimento e em especial conhecimento científico só ganha consenso relativo no interior de comunidades científicas que legitimam determinadas formas de procedimen-

\footnotetext{
4 Domenico De Masi (1999, p. 49) associa a emergência da sociedade pós-industrial aos seguintes fatos, descobertas científicas e eventos políticos: fim da Segunda Guerra Mundial. Projeto Manhattan (1944-45), desembarque na Normandia (1944), descoberta da estrutura do DNA (1953), concentração da mão-de-obra no setor terciário nos EUA (1956), crise pretrolífera (1973). Alguns autores que inauguraram essa discussão (Daniel Bell, Alain Touraine, Ralf Dahrendorf, Alvin Toffler, entre outros) não chegaram a extrair todas as conseqüências teóricas e empíricas das sociedades pós-industriais, uma vez que seus estudos foram feitos ainda no calor daquelas mutações. Mais recentemente, De Masi (op. cit.) e Castells (1999, v. 1. I,II e III) conseguiram avançar melhor na compreensão dessas mudanças. Particularmente, a discussão feita por Castells (1999, v. I), sobre capitalismo informacional, permite uma discussão teórica bastante aprofundada sobre as tendências do capitalismo contemporâneo e as mudanças na organização política, cultural e social. O capitalismo informacional depende de um novo paradigma tecnológico, contendo quatro aspectos complementares: 1) a informação é sua matéria prima: são tecnologias para agir sobre a informação não apenas informação para produzir a tecnologia, conforme o paradigma industrial anterior; 2) todos os processos individuais e coletivos são moldados por essa tecnologia (penetrabilidade dos efeitos das novas tecnologias); 3) a lógica de redes estabelece modelos de comunicação que se adaptam rapidamente à complexidade da informação; 4) flexibilidade e reconfiguração diante das constantes mutações tecnológicas (Castells, 1999, v. 1, p. 78).
} 
tos técnicos, ao produzirem resultados submetidos à apreciação e ao controle da prova pela comunidade de cientistas e ao desenvolverem alguns interesses, em torno a benefícios e a formas prestigiosas de poder ${ }^{5}$. Esta dimensão é captada pela sociologia da ciência.

Atualmente, é incomensurável o número de escritos que apresentam definições, opiniões e concepções sobre o que é ciência; em que pese essa grande quantidade de estudos sobre a matéria, há inúmeras convergências sobre o seu sentido moderno. As teorias científicas seriam extraídas de maneira rigorosa dos fatos submetidos à observação e à experiência. As opiniões pessoais são desconsideradas, bem como os gostos e as especulações derivadas da imaginação. A ciência pode ser confiável porque é um saber objetivamente provado.

Ora, esta visão de ciência pode muito bem ser desclassificada, hoje, como de fato o é, por muitos cientistas, inclusive. Porém, fazia sentido no momento de sua emergência ( século XVII), quando Francis Bacon e seus contemporâneos descreveram com precisão a atitude de seu tempo: ao invés de consultar os escritos de Aristóteles para compreender a Natureza, é necessário consultá-la diretamente. Eis o axioma de Bacon. (Chalmers, 1987, p. 21-22).

De Francis Bacon (Cassirer, 1986) a Niels Bohr (1987), nenhum cientista descartará, no interior do trabalho científico, o papel da experiência. No entanto, a experiência, como tal, é matéria de controvérsias infindáveis, sobretudo quando se passa de um domínio a outro da matéria. A filosofia recupera essa discussão através do debate sobre o que é objetividade e subjetividade (a controvérsia entre materialismo e idealismo) ${ }^{6}$.

$\mathrm{O}$ que vai diferenciar uma querela de outra é o entendimento sobre o papel do observador e o "descritor" da realidade, isto é, os signos lingüísticos ou a teoria explicativa da mesma (a matematização aparece enquanto signo de exatidão).

O conhecimento científico deve obedecer, para Bacon, a um princípio ativo: só compreendemos um objeto quando o temos entre as mãos, para manipulá-lo e dispô-lo de acordo à nossa vontade. ${ }^{\text {? }}$

Os nexos necessários que existem entre os fenômenos empíricos deverão ser desvendados pelo experimento, explicitando os fundamentos racionais, no interior da experiência mesma.

A experiência se apresenta, assim, como uma espécie de "tortura" que deve ser exercida sobre a realidade que aparece sempre como um poder estranho. Daí a dificuldade de se olhar o todo de uma vez. Deve-se, pois, arrancar da realidade pedaço a pedaço, com a ajuda dos instrumentos e armas da técnica.

A experiência da construção do objeto científico, para Bacon, não coincidirá com a impressão direta da realidade, conseguida pelos sentidos, uma vez que o espírito humano não reflete as coisas tais como são; pelo contrário, os fantasmas aparecem misturados aos sentidos humanos. Daí os idola (expressão da ilusão) serem criação do espírito humano, ao contrário das idéias que são produtos do espírito divino. Não seria difícil posteriormente, através do racionalismo iluminista, substituir o espírito divino pela razão científica, pois esta é imparcial e consegue converter verdade em experiência comprovável.

A ordem teórica das observações concretas decidirá, portanto, sobre o valor e o significado objetivo das próprias observações.

5 "O campo científico é um campo social como outro, com suas relações de força e seus monopólios, suas lutas e suas estratégias, seus interesses e seus benefícios" (Bourdieu, 1976, p. 89)

6 Heisenberg (1996, p. 107-108) nos relata um diálogo com Niels Bohr sobre o "objetivo” e o "subjetivo” : “... considero uma grande libertação do pensamento esses avanços que a física obteve nas últimas décadas. Eles mostram quão problemáticos são conceitos como "objetivo" e "subjetivo". Tudo começou com a teoria da relatividade. No passado, a afirmação de que dois eventos eram simultâneos era considerada uma asserção objetiva, passível de ser comunicada de forma inequívoca e passível de verificação por qualquer observador. Hoje, sabemos que "simultaneidade" contém um elemento subjetivo, pois dois eventos que aparecem simultâneos a um observador em repouso não são necessariamente simultâneos para um observador em movimento. Contudo, a descrição relativista também é objetiva, na medida em que cada observador pode deduzir, através de cálculos, o que o outro observador perceberá ou percebeu. Mesmo assim, nos distanciamos do ideal das descrições objetivas da antiga física clássica".

7 Por tratar-se de um modelo ou paradigma de ciência moderna, seguida até hoje, consideramos importante passar em revista alguns dos fundamentos enunciados pela obra de Francis Bacon (1561-1626). A avaliação que apresentamos da visão de ciência em Bacon é de Cassirer (1994, v. 2, p.139-162). 
Para Bacon, não basta deter-se diante da simples comprovação do concreto. Qual seria então o caráter do ser ou da realidade que a experiência deve revelar-nos? A Natureza para Bacon não é um todo ordenado de mudanças e variações sujeitas a leis, mas um conjunto de entidades existentes por si.

Três características básicas estão presentes na nova concepção de Bacon sobre a produção do conhecimento científico: 1) não deter-se diante da simples comprovação do concreto; 2 ) uma vez que considera a natureza e os objetos da natureza como um campo à parte, possível de ser dominado plenamente, a indução pode conduzir gradualmente até as qualidades gerais das coisas, até o descobrimento de suas últimas propriedades (por meio da "contagem" de todos e de cada um dos elementos que integram aquele campo); 3)a teoria baconiana da experiência está intimamente relacionada com outra de suas características, a saber, a separação radical entre observação e teoria.

É evidente que o conceito de ciência vem acumulando sofisticados enxertos de epistemólogos e cientistas, desde que enveredou pelo paradigma acima apresentado. Para Granger (1994), em primeiro lugar, a ciência é visão de uma realidade, uma espécie de "metaconceito", aplicando-se não diretamente a experiências mas a representações de experiências ${ }^{8}$; em seguida, a ciência visa a objetos para descrever e explicar, não para agir. Com esta observação, Granger tenta minimizar a herança cartesiana "tornar-nos como que senhores e proprietários da natureza", justificando essa concepção pelo entusiasmo dos modernos em tirar o máximo proveito da natureza, em benefício humano; finalmente, ainda para Granger (1994), a ciência se preocupa com critérios de validação, devendo indicar a maneira como foi obtido determinado saber, para que suas condições possam ser reproduzidas.

Depois de algum tempo, são conhecidas as críticias dirigidas ao "receituário" científico. As ciências experimentais costumam criticar o "deducionismo" como desvio principal; por sua vez o "inducionismo" também tem demonstrado suas fraquezas. Ora, esse debate é mais profundo e complexo do que a simplificação aqui apresentada.

O objetivo aqui expresso é o de, simplesmente, enunciar alguns princípios fortes que sustentam as bases da teoria da ciência moderna para, em seguida, confrontar com algumas críticas feitas aos seus limites. Neste sentido, foram apresentados alguns poucos enunciados baconianos que, sabe-se, não esgotam o conceito de ciência moderna, porém têm a finalidade de contrapor-se a outras concepções atuais de conhecimento científico.

Já se tornou moda a referência a Feyerabend quando se quer pulverizar o papel da ciência. Sua crítica básica refere-se ao imperialismo do pensamento científico ocidental que se expressa pelo monopólio de regras metodológicas simples e pela legitimidade do argumento da autoridade ( "se a ciência afirma, então!" ), excluindo outros discursos (do senso comum, da arte, da religião, etc.).

Por sua vez, teorias científicas rivais não podem ser intercambiáveis, no plano da crítica, em termos puramente lógicos, uma vez que partem de postulados diferentes. É a famosa tese da incomensurabilidade entre teorias (Feyerabend, 1980, Chalmers, 1987, Granger, 1994).

Como conseqüência, obtém-se uma idéia de que a ciência moderna é pluralista, incapaz de submeter-se a alguns poucos critérios de controle teórico-metodológico. Ao ressaltar a diversidade dos métodos, às lacunas e às precariedades das teorias, Feyerabend coloca a ciência no mesmo plano dos mitos, das religiões e das ideologias, enquanto expressões de entendimento da realidade (Granger, 1994). Para estimular os pesquisadores a saírem da camisa-de-força da ciência, e a buscarem a liberdade frente ao controle que o Estado exerce sobre a ciência, (daí a pecha de anarquista, embora ele mesmo tivesse se auto denominado um dadaísta da filosofia das ciências) Feyerabend propõe o "princípio de proliferação" (um exercício de fustigamento às verdades estabelecidas da ciência). (Granger, 1994).

Para Feyerabend, a metodologia dos programas de

8 "Devemos ter claro que, quando se trata de átomos, a linguagem só pode ser usada como na poesia, pois não se trata de expressar precisamente dados objetivos, mas sim de fazer com que o ouvinte conceba imagens na sua consciência e estabeleça ligações mentais" . (Fragmento do diálogo com Niels Bohr, relatado por Heisenberg, 1996, p. 54) 
pesquisa fornece critérios que auxiliam o cientista a avaliar a situação histórica na qual toma suas decisões; porém, aquela metodologia não contém regras que lhe dizem como deve agir (apud Chalmers, 1987, p. 217).

\section{Rompendo os diques da(s) ciência(s)}

O debate em torno dos limites do conhecimento científico, seja do ponto de vista da racionalidade discursiva ou filosófica, seja do ponto de vista do ceticismo engendrado pela corrida armamentista e pela não resolução dos problemas básicos da humanidade, em especial daqueles que tratam diretamente das condições de sua sobrevivência, fez com que se lançassem sérias dúvidas sobre algumas certezas construídas pela visão iluminista, desde o século XVIII.

Max Weber (1980) em sua famosa palestra de 1919 sobre a Ciência como Vocação interpreta as preocupações tolstoianas (de León Tolstói) sobre a provisoriedade da vida na modernidade, devido justamente à inovação tecnológica, tornando a morte e, portanto, a vida sem sentido. Tanto os existencialistas, principalmente os de vertente heideggeriana, vão tecer críticas violentas ao progresso técnico (Stein, 1997); A Escola de Frankfurt, principalmente Adorno, Marcuse e Habermas, mais recentemente, desenham um futuro alienante e unidimensional, dominado pela técnica e pelo consumismo cultural.

A ciência da física, talvez por ter protagonizado as mais importantes revoluções científicas da era moderna, desde Newton, é a que mais exercitou o debate sobre as certezas adquiridas pela razão e pela experimentação. Em se tratando de uma teoria altamente valorizada e respeitada como ciência, pela comunidade científica, os clamores e as heresias de alguns de seus mais importantes representantes conseguiram influenciar o conjunto da comunidade científica, em escala mundial.

À irreverência científico-política de Feyerabend (1997), relatada em seu último livro autobiográfico, somam-se outras grandes discussões, em especial as de Bohm; Peat (1989), ainda no domínio da física, mas já derivando para uma crítica filosófica do mundo e da ciência, de Prigogine (1987; 1997), de Capra (1994), ainda no âmbito das ciências duras, abrindo-se, porém, para um diálogo amplo com a filosofia, algumas ciências sociais, a estética, a ética, a religião,a política, enfim, com a vida, com a ecologia, tentando recuperar seja algo que havia sido perdido, uma visão holística da realidade, onde nada se exclui, nem a natureza, nem o mito, nem a espontaneidade. As ciências sociais são convocadas um pouco tardiamente para esse balanço da ciência. Edgar Morin $(1991 ; 1994)$ tem sido um dos pioneiros em lançar uma reflexão sistemática, no campo das ciências sociais, sobre a crise do conhecimento científico e sugestões para superar o antigo paradigma.

Envolvidas durante mais de um século em querer provar que também eram sistemáticas, sérias, experimentais em alguma medida, eis que as ciências sociais se defrontam com a relatividade das certezas, no momento em que algumas das outras ciências duras já haviam feito o seu mea culpa. As ciências sociais são então convidadas a fazer um retorno, um quase caminho de volta, no momento ainda em que buscavam chegar a algum lugar garantidamente insuspeito, quer dizer, ao campo das ciências consideradas como tais. Isto não tem nada a ver com o elogio à "frouxidão" das ciências, ou um adeus à disciplinaridade, mas a uma revisão profunda sobre os fundamentos do paradigma dominante de ciência.

Contudo, não basta o diagnóstico das ciências em

9 A discussão sobre as alternativas da produção de conhecimento em base à troca, ao diálogo e à colaboração sobre estudos e pesquisas em comum vem merecendo uma discussão interessante, principalmente no domínio da pesquisa ambiental. O Doutorado em Meio Ambiente e Desenvolvimento da UFPR e também outras unidades de ensino e pesquisa ambiental de pós-graduação, no país e fora dele, vêm enfocando a produção do conhecimento científico a partir de experiências desse tipo (principalmente interdisciplinar). Há um número especial de Cadernos de Desenvolvimento e Meio Ambiente (n. 3, 1996, Doutorado em Meio Ambiente e Desenvolvimento da UFPR) abordando esta questão. Sabe-se que as comunidades científicas começam a reagir às novidades quando estas se tornam "insuportavelmente" impositivas, obrigando-as a tomarem uma posição a favor ou contra; isto começa a ser visível para a interdisciplinaridade, pelo menos em alguns domínios do conhecimento, embora limitados a algumas áreas (meio ambiente, tecnologia, educação, planejamento urbano, desenvolvimento rural e outras poucas mais, teóricas, como a epistemologia). 
crise para fazê-las mudar de rumo. Sabe-se que razões institucionais contam, e muito, para a manutenção dos paradigmas dominantes. Não são todas as disciplinas científicas, nem todas as áreas de conhecimento que estão dispostas ao diálogo multi, inter ou transdisciplinar 9 .

\section{Da indignação moral e política à busca de no- vos referenciais de ciência}

O exemplo talvez mais emblemático de recusa ao modelo de ciência e de denúncia ao monopólio de racionalidade científica dominante, seja o de Feyerabend (1985; 1991).

Como já dito, Feyerabend não reconhece superioridade da ciência sobre outras formas de saber. Mais do que isto, a ciência tornou-se tão opressiva quanto as ideologias que teve de combater antes(1985, p. 296). Talvez a parte mais polêmica refere-se à relatividade do conhecimento científico diante de outras formas de conhecimento:

Por que, diz ele, acreditar que as pessoas que não se guiavam antes por uma concepção científica do mundo, deveriam ser vítimas de ilusões e menos felizes do que aquelas que se pautam hoje, por comportamentos científicos? Possivelmente, aquelas pessoas, de acordo ainda a Feyerabend, não estivessem mais desorientadas do que se está hoje (Feyerabend, 1991, p. 233).

Chalmers (1987, p. 227) contesta a comparabilidade de conhecimentos (por exemplo a astrologia ou o vudu) feita por Feyerabend com a ciência. Por dois motivos básicos: o primeiro, embora Chalmers reconheça a possibilidade de preconceito de sua parte, duvida que o vudu e a astrologia tenham métodos e objetivos claramente definidos; o segundo, pelo fato de a astrologia, o vudu e outros saberes do mesmo tipo não se apresentarem como problemas cruciais para nossa sociedade de hoje, não estaríamos em condições de escolher livremente entre a ciência e o vudu ou entre a racionalidade ocidental e a da tribo dos Nuer, por exemplo.

De qualquer maneira, a crítica que Feyerabend diri- ge à racionalidade científica ocidental, e à sua voracidade discursiva onívora, pode prestar um serviço de crítica política para sua utilização contra outras culturas e saberes. Isto não quer dizer que a crítica de Feyerabend seja extra-epistemológica; ao contrário, o diagnóstico que faz da ciência, tanto de suas práticas, de seus discursos e de seus usos sociais é eminentemente "científico", isto é, construído no interior dos cânones da ciência e comunicado aos seus pares cientistas ${ }^{10}$.

\section{Uma nova ciência: da parte ao todo?}

David Bohm ( 1987, p. 17) parte de um esquema cognitivo complexo para definir o que é a realidade e o que significamos por ela: o que dizemos do mundo nunca é o que dizemos dele, porque aquilo de que desejamos falar não são palavras. A realidade é, assim, mais do que o que significamos, não se esgotando nos conceitos. O famoso quadro do pintor surrealista belga René Magritte seria emblemático neste sentido: ao pintar um cachimbo, acrescenta uma frase que diz: isto não é um cachimbo.

Cada gênero de pensamento, inclusive o matemático, é uma abstração incapaz de abarcar a realidade inteira. E aqui reside uma coisa interessante para a colaboração entre distintos saberes: cada gênero de conhecimento isoladamente tem seus próprios limites, mas junto com outros pode levar o entendimento do mundo muito além daquele feito por uma disciplina, de forma isolada. Este último ponto pode constituir, provavelmente, um dos postulados da interdisciplinaridade.

O conhecimento científico moderno é obrigado a lidar com uma complexidade crescente da realidade. Ao contrário do que poderiam supor os partidários da superespecialização e conseqüentemente da fragmentação do conhecimento, tem-se uma situação de trocas crescentes e sofisticadas, tanto no interior dos processos cognitivos e técnicos (o que implica o desenvolvimento de novas linguagens e tecnologias), como nas formas de intercâmbio mais geral entre comunidades científicas e destas com

$10 \mathrm{Um}$ intenso debate sobre diferenças e semelhanças entre conhecimento tradicional e científico vem sendo feito desde os anos 60 entre filósofos, sociólogos, epistemólogos, antropólogos e outros especialistas. Veja-se a esse respeito (Lévi-Strauss, Horton, Habermas e Boaventura Santos) dentre muitos outros. 
o público ou com a sociedade, engendrando novas formas de relacionamento entre produção e consumo de saberes científicos e outras formas de saberes. Giddens $(1989 ; 1991)$ chamará a isto de dupla hermenêutica ou de reflexividade ${ }^{11}$. Na medicina e na produção de medicamentos, por exemplo, existe uma via de mão dupla. Se fosse dar crédito somente à eficácia e ao monopólio semântico do discurso científico da alopatia, não haveria como explicar o contra-efeito, produzido por movimentos sociais alternativos críticos aos tratamentos tradicionais, sobre a adoção de novas formas de tratamento homeopático. Em conseqüência disto, os sistemas peritos (laboratórios, universidades, etc.) absorvem a crítica e se ajustam novamente a esquemas de legitimidade simbólica, incorporando reivindicações mais amplas da sociedade, no domínio da saúde.

Ao mesmo tempo em que o conhecimento científico se apropria da produção dos saberes sociais, torna-se um campo simbolicamente protegido, tendendo a se instuticionalizar e a encerrar-se em rituais corporativos.

Na linha desta argumentação, Morin (1991, p. 56) afirma que os conceitos científicos extraídos da experiência social se emanciparam e se transformaram. O conceito de energia, central na física moderna, nasce da junção das noções de força e de trabalho, durante a primeira Revolução Industrial. Força, trabalho, energia, ordem, desordem, conservam seus vínculos com a vida comum. Morin apóia-se em Bronowski, para dizer que o conhecimento científico não pode sempre dispensar as noções do senso comum, embora este último sofra influências do primeiro, que lhe impõe uma nova visão de mundo, inicialmente com a concepção mecanicista-determinista do Universo, e depois, mais recentemente, com a teoria do big bang, das galáxias, da anti-matéria, dos buracos negros, e assim por diante.

Alguns pontos críticos devem ser localizados para conduzir o debate sobre o conhecimento científico e sua crise atual. Desta crise, emergem o diagnóstico e a discussão sobre o alcance de um pensamento "complexo".
Além disto, permance em aberto o debate das especializações, da classificação dos conhecimentos por áreas (por exemplo, ciências humanas, ciências da vida e da natureza, ciências tecnológicas, etc.), da possibilidade de colaborações e de diálogos institucionalizados entre saberes disciplinares, da utopia (ou ingenuidade?) de uma teoria do conhecimento unificada, entre outros pontos, para uma futura agenda de debates que requerem aprofundamento.

A artificialização do mundo, associada a interesses corporativos instalados e cristalizados institucionalmente, mas além disto, um mundo real que funciona desta maneira, fazem com que a realidade seja ainda representada de forma compartimentalizada, isolada e com poucas perspectivas de comunicação entre si. Ora, se isto permitisse um funcionamento auto-sustentado ( no qual coexistam diversidade cultural, capacidade de renovação dos recursos naturais e reprodução social ), sem ruídos para os seres humanos, uma reprodução das sociedades de maneira relativamente equilibrada, uma forma de produção e apropriação material, isto é, mecanismos de trocas entre sociedades e natureza sem grandes perdas para ambos os sistemas e para a vida na Terra, então não faria algum sentido buscar questionar como e para quê se produz ciência nas sociedades contemporâneas.

O diálogo de saberes não aparece, certamente, como signo de civilidade entre os cientistas, mas deriva da impotência destes em resolver grandes desafios, para cada uma das disciplinas isoladamente. Dessa impotência e dessa ignorância pode nascer um princípio ativo que oriente os cientistas e pesquisadores para uma nova pedagogia da ciência, para novas colaborações, através de trocas, parcerias e consórcios fecundos. No domínio das relações sociedade-natureza, certamente, justifica-se cada vez mais novas associações, para produzir novos conhecimentos e engendrar práticas diferentes e alternativas ao modelo predatório de civilização instaurado pela economia de mercado e pelo produtivismo exacerbado.

11 Giddens (1989, p. 303) define dupla hermenêutica como "a interseção de duas redes de significado como parte logicamente necessária da ciência social, o mundo social significativo constituído por atores leigos e as metalinguagens inventadas por cientistas sociais; há uma "oscilação" constante de uma rede para outra envolvida na prática das ciências sociais".

A reflexividade da vida social moderna, segundo o mesmo autor (Giddens, 1991) "consiste no fato de que as práticas sociais são constantemente examinadas e reformadas à luz de informação renovada sobre estas próprias práticas, alterando assim constitutivamente seu caráter". 
O que não é consensual ainda, neste âmbito, é qual o grau de intervenção tecnológica que deve ser aplicado nos sistemas produtivos ${ }^{12}$. Isto por uma razão simples de entender: as decisões sobre os caminhos do desenvolvimento são objeto de negociações e conflitos políticos. Hoje, reconhece-se que a tecnologia não é boa nem má em si, porém ela não é neutra, uma vez que reflete uma cultura científica e tecnológica, objeto de apropriação e de utilização social. Ela também é fonte e objeto de poder.

$\mathrm{O}$ que nos forçou a enveredar pelo caminho da cientificidade moderna? Prigogine (2000) utiliza-se de uma metáfora ${ }^{13}$ para referir-se à evolução incerta dos sistemas, através de "bifurcações". Essas bifurcações aparecem em pontos especiais, subdividindo-se em "ramos". Todos os ramos são possíveis, mas só um deles será seguido. Como a vida em sociedade combina acaso com necessidade, a escolha de caminhos e alternativas depende, em grande medida, do esforço deliberado e negociado de seus agentes, isto é, de seres inteligentes (embora movidos à emoção). Construir sociedades não é apenas questão de vocação e destino, mas de um conjunto de ações deliberadas. Quando os seres humanos tomam consciência de seus problemas, sem subestimálos, existe uma grande probabilidade de superá-los. É também provável que a civilização atual se dê conta do modelo dominante de sociedade, em grande parte excludente de seus próprios condutores ("a máquina expulsou o maquinista", no dizer de Horkheimer) e das conseqüências trágicas de expropriação da natureza em curso.

\section{Ciências Sociais e Naturais: o que as aproxi- mam e as diferenciam?}

Ao comparar o papel do observador nas ciências sociais e nas ciências naturais, Morin (1994, p. 302-5) percebe algumas diferenças. Nas ciências sociais o observador é ao mesmo tempo alguém que perturba e é perturbado. Ele é perturbado pelo seu lugar. Se na física, por exemplo, não há um lugar para um observador "universal", ainda menos para a sociologia. O observador social quer entender e conhecer a sociedade, mas não é exterior a ela; é um elemento dela, e apesar de querer colocar-se acima dela, como observador objetivo, sua ação de conhecer perturba e modifica o fenômeno observado. Neste sentido, nas ciências sociais o observador/nomeador é sujeito entre sujeitos.

Se nas ciências da natureza pode-se excluir o sujeito, em primeiro grau, embora não se possa excluir de vez o observador/nomeador, nas ciências sociais não se pode excluir de vez nem o observador nem o sujeito. Morin (idem) faz a seguinte indagação: como proceder ao se expulsar o sujeito nas ciências humanas e sociais, como se fosse um resíduo vergonhoso, concessão às suas ilusões subjetivas, para substituí-lo por palavras, cifras, regularidades, ou vozes que pertencem a uma espécie de "universal objetivo"? Paradoxalmente, quando se pretende falar em nome de um universal é que aparece mais fortemente os limites de uma certa subjetividade.

A história das ciências antropo-sociais são reveladoras de uma certa ilusão neste sentido, mas também de um certo reconhecimento auto-crítico na superação dessas dificuldades. A auto-crítica da antropologia, por exemplo, aparece quando utiliza conceitos e categorias próprias à cultura do observador para julgar culturas diferentes: o "primitivo" era irracional e místico, em oposição ao homem moderno.

Foi necessário um conhecimento mais aprofundado das civilizações não-ocidentais, bem como uma autocrítica ao colonialismo implícito nas categorias de análise dos observadores, duvidando do próprio Ocidente e de suas vantagens, para que a teoria antropológica

12 Uma vez mais devo a Rogério Parentoni Martins a seguinte observação: "Uma crítica recente e proposta de uma ética na pesquisa tecnológica partiu de Bill Joy, cientista da Sun Microsistem, uma das figuras proeminentes do círculo da alta tecnologia, na Revista Wired. Para muitos, foi surpreendente ouvir desse guru da tecnologia que os cientistas deveriam se deter quando pensassem avançar na engenharia genética, robótica e nanotecnologia, pois os humanos não estão preparados para serem deuses. Portanto, antes de passarmos de um ponto do qual será impossível retornar é preciso parar e pensar. A única alternativa é a limitação do desenvolvimento de tecnologias demasiadamente perigosas quando se procuram certos tipos de conhecimento ".

13 Aliás, as metáforas são recursos crescentemente utilizados pelas ciências modernas, para simular a realidade e a vida. Talvez este seja um signo positivo de vincular o conhecimento científico e a pesquisa com o cotidiano e a contingência da vida real. 
alcançasse um certo distanciamento de seus conteúdos. Se para Morin isto representa um avanço, o problema persiste em termos de sua resolução, a saber: como perceber as sociedades que aparecem tanto através de seus mistérios, de seus enigmas como de suas riquezas?

Uma vez explicitados esses problemas, há duas vias possíveis para adotar, a fim de superá-los. Ambas vias são, simultaneamente, contraditórias e complementares, a saber: o "entrismo", cuja estratégia é de se inserir para conhecer uma sociedade, não mais se contentando de ser informado por alguém cuja leitura do real já está impregnada de seletividades arbitrárias; praticar o autodistanciamento, como segunda via, em relação à nossa própria civilização. Essa dualidade é formulada da seguinte maneira, por Morin (1994, p. 304): não se pode entrar totalmente em outra cultura; não se pode sair completamente da sua, porém nosso espírito pode conduzir um jogo entre uma e outra para tentar reconhecer suas respectivas singularidades ${ }^{14}$.

A sociologia, por sua vez, apresenta outras dificuldades metodológicas, para a construção do tema ou do objeto de análise. Há uma dialética intrincada que confunde sujeito e objeto: os indivíduos não estão em sociedade como se estivessem no interior de uma caixa. As interações entre os indivíduos produzem a sociedade, que não pode existir sem eles; porém, a sociedade retroage sobre os indivíduos humanos, uma vez que ela proporciona a eles a cultura, a linguagem, os conceitos, a educação, a segurança, etc. Produzimos uma sociedade que nos produz. Fazemos parte da sociedade que faz parte de nós.

Um pensamento parcial, que separa sujeito e objeto, neste domínio, é um pensamento mutilador. Não nos encontramos somente em um lugar específico da socie- dade; também a sociedade, enquanto totalidade singular, está em nós (Morin, 1994, p. 305).

Em que medida se pode, portanto, buscar similitudes e diferenças entre ambos campos discursivos em questão (ciências sociais e naturais)? Conforme referência anterior feita às ciências sociais, estas buscavam, em grande medida, espelhar-se em procedimentos metodológicos análogos aos utilizados nas ciências naturais, (experimentação, indução e generalização). Ora, estas últimas sofrem intenso bombardeio crítico da filosofia da ciência, onde as observações sobre a realidade não são isentas de teoria, e considera-se a ciência como um esforço interpretativo, de modo que problemas como significado, comunicação e tradução se tornam imediatamente relevantes para as teorias científicas (Giddens; Turner, 1999, p. 9) $)^{15}$.

Conforme Giddens; Turner (1999, p. 10) a pluralidade de visões no campo das teorias sociais liberou os teóricos da onerosa carga diante do compromisso de fidelidade em relação aos cânones rígidos que certos postulados universais mantinham com suas matrizes filosóficas (positivismo, marxismo, funcionalismo, etc.), a tal ponto de se perguntarem qual a importância da teoria social para aqueles que se dedicam, especialmente, à pesquisa empírica.

Derivou-se daí um profundo rompimento entre "pesquisadores" - que talvez ainda se considerem muitas vezes "positivistas" - e teóricos - que agora aparecem com múltiplos rótulos (Giddens; Turner, 1999, p. 10).

Resumidamente, o que se pode considerar das diversas mudanças, especialmente por parte das ciências sociais, ocorridas no padrão de referência à cientificidade, é a difusão de um tipo de racionalidade

14 Isso nos faz lembrar de uma passagem da obra de Lucien Goldmann, quando discutia o mesmo problema: como não podemos ser totalmente objetivos em ciências humanas, não há razão para advogarmos a arbitrariedade intencional. Para minimizar o risco da subjetividade, na pesquisa social, o pesquisador necessita "exorcizar" permanentemente seus "fantasmas" isto é, questionar-se sobre suas próprias crenças, preferências, seleção do tema a ser estudado, metodologia escolhida, etc.

15 "O resultado dessas mudanças foi a proliferação de abordagens no pensamento teórico. Certas tradições filosóficas, antes pouco conhecidas ou até ignoradas, passaram a se destacar: a fenomenologia, particularmente a associada aos escritos de Alfred Schutz; a hermenêutica, como a desenvolvida na obra de Gadamer e Ricoeur; a teoria crítica, sobretudo a representada em época recente pelos trabalhos de Habermas. Além disso, tradições de pensamento mais antigas, como o interacionismo simbólico nos Estados Unidos e o estruturalismo ou pós-estruturalismo na Europa, se revitalizaram e começaram a ser examinadas com novo interesse. Acrescentem-se a elas tipos de pensamento mais recentemente desenvolvidos como a etnometodologia, a teoria da estruturação e a 'teoria da prática', associada em particular a Bourdieu" (Giddens; Turner, 1999, p. 10). 
cientificista (discursos e procedimentos metodológicos) cuja centralidade se irradiava desde as ciências naturais até as demais teorias. Ao sofrerem críticas do seu próprio interior, pela filosofia da ciência natural, as ciências naturais internalizam outros referenciais epistemológicos e acabam, assim, irradiando um certo grau de incertezas para o domínio das outras ciências, em especial das ciências sociais. Ao contrário do que se poderia esperar, isto é, de um abandono de propostas rigorosas em relação ao trabalho sistemático, de pesquisa e de debate teórico, nas ciências sociais acaba ocorrendo uma valorização de outras vertentes teóricas.

\section{Em busca de qual novo paradigma?}

Parece que a seguinte fórmula de Morin (1994) traduz a inquietação de um bom número de pesquisadores que vem transpondo fronteiras disciplinares (os famosos passeurs de frontières): o específico da teoria não é reduzir o complexo ao simples, mas traduzir o complexo em teoria (Morin, 1994, p. 315). Do elementar ao complexo, do determinismo à ordem/desordem/organização, tal tem sido a trajetória recente da física. O complexo estaria instalado em todas as dimensões da realidade, do plano macro ao micro.

O complexo é aquilo que é tecido juntamente, elementos heterogêneos inseparavelmente associados, paradoxo do uno e do múltiplo. Tecido de eventos, ações, interações, retroações, determinações e acasos do mundo fenomenal. A desordem faz parte da ordem. A ciência clássica, ao evacuar o incerto, o imponderável, o ambígüo, reteve a ordem, simplificando a realidade ao extremo.

Até então espontâneo e inconsciente nas formulações científicas, o pensamento complexo irrompe na crise contemporânea dos pensamentos políticos e científicos e exige uma consciência de sua própria complexidade e da complexidade do real. Da consciência de uma consci- ência mutilada e do sentimento de reformar nosso pensamento, emerge a necessidade de um pensamento complexo.

Cada vez mais o pensamento complexo exige comunicação entre o objeto e o meio, entre o observado e seu observador (Morin, 1994, p. 319).

Conforme Prigogine, as recentes ciências da complexidade negam o determinismo; insistem na criatividade em todos os níveis da natureza. O futuro não é dado.

Para Castells (1999, p. 81) a complexidade deve ter surgido do reconhecimento de que a Natureza e a sociedade possuem a faculdade de produzir, acidentalmente, descobertas felizes e inesperadas; processo contínuo, ações deliberadas e interações exclusivas seriam a sua marca. A tecnologia moderna evoluiria para a abertura de rede, com acessos mútiplos.

Já é bastante comum a associação que alguns autores fazem entre crise de sociedade e de civilização com crise de modos de pensamento e de produção do conhecimento. $\mathrm{O}$ desespero em verificar a impossibilidade de retorno a estágios anteriores de sociedade, impõe uma espécie de fuga para o futuro o que obriga às sociedades e aos seus agentes uma pausa para considerar possibilidades de mudanças no próprio significado de ciência. Para Bohm; Peat (1989) não se necessita tanto de novas idéias científicas, mas de saber como a ciência, baseada ainda numa atitude fragmentária perante a vida, poderá alcançar o âmago dos reais problemas. Não se trata de acumular mais e mais conhecimentos. Foi a falta de sagacidade e de discernimento a causadora dos problemas mais dramáticos do mundo e não propriamente a ausência de conhecimentos ${ }^{16}$.

Somente a criatividade na vida global poderá restabelecer o princípio da totalidade, na vida moderna, desbloqueando e descondicionando os sistemas sócioculturais dominantes. Há três atitudes básicas da mente perante a vida global: a científica, a artística e a religiosa.

Para Bohm; Peat (1989, p. 304), viver de modo cria-

16 John Horgan (1998) produziu um interessante livro, entrevistando os top da ciência mundial (a maioria deles Nobel), com as seguintes questões: "Quais são os limites da ciência, se é que existem: será ela infinita ou tão mortal quanto nós? Nesse último caso, seu fim está à vista? Está perto de nós?” (1998, p. 15). "Quando falo em ciência, não me refiro à ciência aplicada, mas à ciência na sua forma mais pura e grandiosa, a busca humana primordial de compreender o universo e o nosso lugar dentro dele.As pesquisas futuras talvez já não tragam grandes revelações ou revoluções, mas apenas resultados menores, acréscimos" (1998, p. 17). 
tivo exige uma percepção muito sensível das ordens e estruturas das relações entre indivíduos, sociedade e natureza. Diante disto, a criatividade pode desabrochar. A palavra de ordem é, portanto, fazer renascer a criatividade nas pessoas, entre elas e delas para com a natureza: "o desafio que se põe a humanidade é único, porque nunca antes ocorreu algo de semelhante. Não há dúvida de que precisamos de nova onda criativa para poder enfrentá-lo. Não se trata aqui precisamente de uma nova maneira de fazer ciência, mas sim de uma nova abordagem da sociedade e, muito mais ainda, de uma nova espécie de consciência" (Bohm; Pet, 1989, p. 272).

Para Bruno Latour ( 2000 ), as disciplinas científicas são uma verdadeira Babel, agravadas pela divisão em distintos objetos de conhecimento. A fragmentação não só de disciplinas, mas de especializações no interior de uma mesma disciplina, impede o diálogo entre especialistas. A especialização neste caso não seria algo de negativo, em si, desde que permitisse uma troca que partisse de um núcleo de problemas e métodos comuns. Estranha o autor, entretanto, da dificuldade de especialistas se colocarem de acordo sobre, por exemplo, a existência de um campo de estudo chamado "ciência, tecnologia e sociedade". O que seria recomendável, segundo Latour, é que fossem definidos alguns conjuntos de conceitos suficientemente resistentes, capazes de transitar por algumas das disciplinas afins.

Pareceria que a idéia de uma visão integradora de ciência (diga-se unificadora) não aparece apenas do lado dos críticos da fragmentação do saber, mas também daqueles que acreditam ser a especialização decorrente de um aspecto cientificamente positivo. Embora ambas posições, antagônicas, em um certo sentido, defendam uma certa "unicidade" da ciência, é de fato a confusão semântica do que representa essa unicidade que deve ser esclarecida. Profundos e insanáveis significados contidos nestas distintas concepções nos remetem a resultados bem diferentes sobre o que é ciência.

Começando pelo lugar da indução, da empiria e da simbolização da linguagem científica, tem-se que o neopositivismo lógico elege a ciência como a linguagem e o discurso por excelência do conhecimento moderno. A unidade "diz respeito, ao mesmo tempo, a uma uniforme estruturação lógico-matemática do conhecimen- to científico e à possibilidade de exprimir numa linguagem única seus conteúdos empíricos, em qualquer área" (Granger, 1994, p. 41).

A visão atual de uma possível unidade do conhecimento funciona mais como uma alusão, por analogia, à idéia de refundir o que está disperso. Esta idéia está ainda nos preliminares de sua construção e não poderá operar com a arrogância de uma superciência, pois o que caracteriza a complexidade moderna é a pluralidade de visões, a multiplicidade de concepções e de identidades culturais, portanto de saberes plurais. O que uma nova "cientificidade" deverá permitir seria o livre trânsito de saberes, através de vasos comunicantes, onde não haja lugar para a arrogância do seu olhar sobre outras formas de saber, incluindo-as no patrimônio cultural da diversidade de saberes da humanidade. Por outro lado, a ciência não prescindirá dos saberes disciplinares, uma vez que a divisão técnica do trabalho científico é um requisito da complexidade tecnológica. O que deverá ser implementado, sob o signo de uma nova criatividade, conforme apresentado por Bohm e Peat, é a tomada de uma consciência prática de fazer conhecimento diferente, do ponto de vista individual e social, isto é, institucional. Não há mudanças de modelos do pensamento sem uma reforma concreta do modo de se produzir conhecimento. A idéia de uma possível unidade da ciência poderá tardar, em função de interesses, inclusive antagônicos, existentes na sociedade como um todo e em particular nas instituições, as agências peritas do conhecimento, que mobilizam recursos muito caros ao sistema de mercado: patentes, capital, tecnologia e know how. Talvez a cautela de Granger (1994, p. 41-42) neste assunto possa ter sua razão, ao entender a unidade da ciência num sentido mais fraco, fazendo justiça à pluralidade de métodos e de objetos mas que virá associada à unidade de uma comum visão de conhecimento.

\section{Perspectivas para a ciência e a sociedade}

$\mathrm{O}$ entendimento e as críticas feitos às sociedades da hiper-especialização não devem ser associados a uma atitude de retorno a algum elo perdido, quando o ser humano perdeu seu estado de graça, tornando-se dessa 
maneira infeliz. Muitas coisas de errado, entretanto, deram curso a desvios na forma de planejar as sociedades e consequientemente de se apropriar dos meios de vida material (natureza), transformando permanentemente as condições de vida material e espiritual, em especial nos últimos 200 anos de Sociedade Industrial.

A divisão social do trabalho nas sociedades pósindustriais, reproduz ainda,em grande medida, os resquícios da organização taylorista do trabalho.

A obra de F.W. Taylor (1856-1915) aparece no momento da segunda revolução industrial, da fase de produção em série, que necessita de uma organização do trabalho. Passando da condição de operário a de contramestre, defronta-se com o problema da "gazeta" sistemática; constata que seus antigos colegas não trabalham como deveriam ou poderiam. Taylor buscará desenvolver a idéia de que todo trabalho industrial é capaz de receber um tratamento científico. Nesta visão está implícita a separação entre concepção e execução do trabalho. O cálculo e o planejamento científico do trabalho não deverão ser feitos pelo operário. Essa concepção chega à seguinte conclusão: o melhor conhecedor do trabalho do mecânico não é o próprio mecânico. Deve-se retirar-lhe sua iniciativa. Implícita a esta ideologia, está o sentido de fazer aumentar a produtividade do trabalho.

"Vocês não estão aqui para pensar" costumava dizer Taylor aos operários. Dirige-se ao operário, encarregado de aplicar seu método, da seguinte maneira:

você está vendo este homem... então, você fará exatamente o que ele pedir. Quando ele disser para pegar uma chave, você a tomará e a transportará; quando ele ordenar para sentar-se e descansar, você se sentará. Você agirá exatamente desta maneira durante todo o dia. E sobretudo, você não discutirá... (apud Bernoux, 1985, p. $63)$.

A ciência taylorista tem a mesma ambição utópica de regulação das relações humanas pela ciência e pelos seus detentores. "A administração das coisas substituirá o governos dos homens", conforme a regra positivista de Saint-Simon, guiava a lógica de Taylor. Quatro são os princípios básicos da administração científica: 1) o estudo de todos os conhecimentos tradicionais, seu registro, sua classificação e sua transformação em leis científicas; 2) a seleção científica dos operários e o aperfeiçoamento de suas qualidades e conhecimentos; 3) a aplicação da ciência do trabalho por operários cientificamente treinados; 4) a divisão quase igual do trabalho executado na empresa entre os operários e os membros da direção (Bernoux, 1985, p. 65).

Se estes princípios forem encontrados na prática da concepção e execução do trabalho científico nas chamadas agências de conhecimento (laboratórios, universidades, escolas técnicas, etc.) não é mera coincidência. São racionalidades do sistema de mercado, de conceber e executar tarefas, que impregnam o ethos do trabalho e da ciência. É evidente, porém, que esta concepção limitada, opressiva mesmo, da organização e do trabalho tem sido sistematicamente bombardeada pelos próprios trabalhadores, as maiores vítimas do processo.

No dizer de Bohm (1985, p. 25), é ingênuo pensar que a ciência será sempre o que é hoje. Sendo o resultado de um processo histórico, envolve muitos elementos fortuitos. Por isto, devemos buscar compreender como chegamos ao presente modo fragmentário de abordagem. Devemos meditar sobre o que poderia ter acontecido se o passado tivesse explorado a fundo outros caminhos possíveis de produzir conhecimento, um pouco naquela perspectiva, abordada por Prigogine, da bifurcação e da emergência de "ramos".

David Bohm (1989, p. 19-21) nos brinda com as seguintes passagens sobre o saldo negativo da especialização fragmentária: Outrora havia uma visão global geral do universo, da humanidade e do nosso lugar no todo. Não havia separação real entre a ciência, a arte e a religião. Com o decorrer do tempo essa especialização, progressivamente mais estreita, acabou resultando no nosso modo atual de abordagem, que é em grande parte fragmentário. Possivelmente a física seja a maior responsável pelo estado de coisas na ciência, pois se tornou o modelo ou ideal de todas as outras ciências. A matemática, por sua vez, pretende analisar o que quer que seja, até chegar a elementos independentes, e encoraja-nos a esperar que qualquer problema se possa decompor em

17 “Usávamos então uma analogia inspirada na visão humana. Os pormenores daquilo que vemos são registrados numa pequena região no centro da retina. Se este for destruído, perde-se a visão em pormenor, mas mantém-se a visão geral, que provém da zona periférica 
fragmentos separados ${ }^{17}$. Embora dentro da ciência ainda exista um movimento de síntese, visando a descoberta de contextos mais vastos e leis mais gerais, o que prevalece é a análise e a fragmentação dos fatores chaves de cada situação. Com isto, os cientistas buscam habilitação para exercer o seu poder de previsão e domínio sobre as coisas. Esta lógica acaba se estendendo para outras ciências, como a química, a biologia, as neurociências, inclusive a economia e a psicologia. De uma maneira geral, tudo isto é sacrificado em nome de um certo progresso.

Desafio titânico para uma nova ciência? Talvez uma nova atitude que dependa de uma vontade conscientemente orientada. Essa orientação, além do mais, reflete uma cultura institucional e social, é alvo de embates e de interesses em conflito, esforço de busca de novas racionalidades ambientais, conforme Leff (1994. p. 17-84).

\section{Algumas considerações finais}

Qualquer balanço que se faça, sempre é provisório. Com maior razão, a provisoriedade aparece quando tratamos de uma realidade tão complexa e mutável quanto a construção social da ciência, uma vez que esta se situa na interface do mundo das realidades materiais e simbólicas: no espaço das restrições, da escassez, das apropriações conflitivas, mas também das idealidades, dos projetos e da imaginação humana.

Percebemos que as ciências se disputam porções de representação do mundo, mas o fazem desde uma perspectiva de racionalidade historicamente estabelecida, na modernidade; a especialização não advém apenas de razões práticas, isto é, da busca de uma maior eficiência, mas e sobretudo da crença de que essa maneira é a que melhor atende ao modelo de "fabricação" do mundo das mercadorias. Ora, a crença não é apenas subjetiva porque projetada no coração e na mente das pessoas.
É objetiva, igualmente, porque é ela que molda os contornos de um certo desejo social, é o amálgama entre o objetivo e o subjetivo, razão de ser e de existir. Uma crença só se torna ideologia quando ela se impõe como dominante. Assim é e tem sido em vários domínios da sociabilidade humana. Quando os calvinistas forjaram seu ethos diante do trabalho, de um projeto ético-político diante de uma realidade em rota de colizão com a secularização, elegeram algumas afinidades eletivas (comportamentos individuais, formas de se relacionar em família, repressão ao erotismo, atitudes místico-masoquistas, horror ao ócio, concupicência enrustida em relação ao dinheiro, subordinação ao tempo mecânico, etc.), modelando um estilo de vida ideal a ser seguido que funcionava ao mesmo tempo como controle repressivo para aqueles que não adotavam semelhante padrão de conduta.

É pelo fato de uma ideologia ser dominante que se torna vulnerável. Paradoxalmente, aquilo que é objeto de idealização é o que mais rapidamente pode se esfumar, uma vez que é simulacro de um certo desejo coletivo idealizado, mas permanentemente alimentado, ${ }^{18}$ espécie de teatro de sombra que simula a realidade.

Está, portanto, ao alcance das práticas e das representações humanas em sociedade, tanto adotarem padrões de condutas que, pela repetição, se cristalizam em estruturas institucionais de funcionamento, como em contestálos. Este parece ser o caminho das práticas e das simbolizações relativas à ciência, na modernidade: uma forma dominante de processá-la e um campo fértil de contestação, uma vez que os tempos modernos são feitos de pluralidade de sentidos, em que pese a mania de insistir que a globalização tornará o mundo igual e único.

Como foi visto, através do presente texto, a racionalidade científica ocidental forjou um modelo de cientificidade, ungido pelo consenso das comunidades científicas, porém atravessado por conflitos filosóficos e epistemológicos, que se impôs no modo de fazer e de

da retina. Todavia, se for esta a zona danificada, ainda que o centro se mantenha intacto, todos os pormenores perdem significado. Por analogia, perguntamo-nos se a ciência corre o risco de sofrer um 'danifício' semelhante na sua visão. Ao dar demasiada ênfase à matemática a ciência pode perder de vista o contexto mais geral” (Bohm, 1989, p. 19).

18 As sociedades contemporâneas estão terrivelmente equipadas não apenas para a eficácia da guerra mas para a persuasão pelo consumo. As carências e contingências reais podem ser supridas por uma espécie de voracidade onívora simbólica: um certo desejo permanente de desejar, espécie de narcisismo coletivo. 
dispor institucionalmente a construção da ciência. Assim, a ciência se tornou uma representação sobre como melhor conhecer a realidade e como melhor dispor dela. Tornou-se conhecimento aplicado, uma vez que o funcionamento das sociedades modernas impôs a apropriação e a transformação da natureza, de forma incontida e ilimitada; a contemplação nestas sociedades, diferentemente das sociedades não-produtivistas, é ativa diante da materialidade, não se contenta em observar, deve experimentar e submeter o real ao ideal e vice-versa; fragmenta o mundo e o desejo, mas se impõe a apropriação como meta. Portanto, é funcional para os resultados esperados pela lógica do sistema de produção e de apropriação pelo mercado. Essa racionalidade de conceber e de transformar o mundo não internalizou, contudo, mecanismos de auto-proteção, uma vez que não conseguiu prever uma série de efeitos inesperados, muitos deles perversos, o que obriga as sociedades a reverem o desenho desse artefato que é a racionalidade científica; sua caixa-preta deve ser aberta para entender os sinais que emite e localizar os limites de seus mecanismos, incapazes de registrar alertas cruciais para a sobrevida na terra e para as iniquiidades sociais (má distribuição das riquezas, ausência de proteção social e outras mazelas oriundas do modelo produtivista dominante).

A modernidade, porém, é um espaço de conflitos e de dissensos. Através deles será possível contestar a hegemonia das formas de conceber e de transformar o mundo, de reaprender criticamente as lições do presente e do passado, revalorizar o que foi desvalorizado (as formas de apropriação da natureza, a cultura sobre os bens naturais nela existentes, principalmente na presente era da biodiversidade, da engenharia genética e de outras expressões tecnológicas de ponta). Outro ponto de importância para o conhecimento científico é a inclusão da ética na pauta da agenda sobre o desenvolvimento das sociedades humanas: a inclusão da sustentabilidade e do horizonte do tempo desse desenvolvimento, isto é, preocupar-se com o presente e o futuro, espelhando-se no positivo do passado, parece ser uma novidade para os seres humanos refundarem outros contratos, naturais e sociais.

Porém, de nada adianta se o discurso se torna a logomarca, se as intenções forem substituídas pela logocracia e logomaquia das manifestações e pela burocracia dos diagnósticos. De nada adianta se cada saber ficar confinado em sua casamata, defendendo-se de ataques imaginários mas retaliando o mundo com seu discurso limitado. O diálogo de saberes, não em final de semana, mas como projeto fundante de um novo praticar conhecimento sobre a natureza, a sociedade e suas confluências e divergências, praticar a inclusão de outros conhecimentos, explicitar as visões que os atores do desenvolvimento têm a dizer, embora não possuidores dos códigos científicos, saber ouvir, não deixando aos confessores e aos psicanalistas apenas a arte de interpretar os sintomas, e sobretudo dizer e fazer diferentemente, eis o grande desafio que espera por todos aqueles que pretendem encarar o mundo da ciência, da natureza e da sociedade, de uma outra maneira.

As ciências sociais e naturais estão convocadas, juntamente com as outras expressões de produção social do conhecimento, para esse colóquio, em nova parceria, para tentar desatar muitos nós que nos prendem a visões e a práticas limitadas de relacionamento entre os seres humanos em sociedade e com a natureza. Tornar um mundo viável e não apenas possível, eis o grande desafio para os que começam a perceber que fazer ciência, em novas bases, é menos complicado do que parece mas é mais complexo do que efetivamente se apresenta.

Finalmente, essa tentativa de diálogo entre diferentes saberes nos convida a uma tarefa ingente e abrangente, qual seja, a de uma reeducação não apenas pelos sentidos mas também pela razão: ambos não são contraditórios. O especialista da ciência não poderá deixar de tentar construir uma visão de generalista (pela estética, pela ética, pelo conhecimento espontâneo e criativo - popular, religioso, etc.), reeducando-se (trocando) com os outros. Porém, a construção de um conhecimento interdisciplinar exige imaginação e prática, além de remeter-se concretamente aos desafios que a sociedade lança aos seres humanos (homens e mulheres) em permanente diálogo com a natureza.

No nosso caso, é dessa experiência e desses desafios que pretendemos participar e compartilhar. Uma vez mais, as sociedades humanas de hoje devem buscar ser viáveis e não apenas possíveis.

Uma agenda socioambiental exigirá o concurso desse diálogo interdisciplinar, no qual as ciências da vida, da natureza e da sociedade buscarão novas alianças. Não será tão relevante, talvez, o nome que se dê a esse novo 
FLORIANI, D. Diálogos interdisciplinares para uma agenda socioambiental:

"contrato de saberes" (inter/trans/disciplinaridade?). Mais importante é a mudança de atitude diante da trama complexa da vida, tecida entre os seres humanos em sociedade e com a natureza.

\section{REFERENNCIAS}

BERNOUX, Philippe. La Sociologie des Organisations, Paris: Éditions du Seuil, 1985.

BOHM, David; PEAT, F. David. Ciência, ordem e criatividade. Lisboa: Edit. Gradiva, 1989.

BOHR, Niels. La teoría atómica y la descripción de la Naturaleza - Cuatro ensayos precedidos de una introducción. Madrid: Alianza Editorial, 1988.

. Física atômica e conhecimento humano. Rio de Janeiro: Contraponto, 1995.

BOURDIEU, Pierre. Le champ scientifique. In: Actes de la recherche en sciences sociales, Paris, n. 2-3, 1976.

CAPRA, Fritjof . O ponto de mutação. São Paulo: Cultrix, 1994.

CASTELLS, Manuel . A sociedade em rede. São Paulo: Paz e Terra, 1999.

CASSIRER, Ernst. El problema del conocimiento. México: FCE, 1993. v. 2.

CHALMERS, Alan F. Qu'est-ce que la Science? Paris: La Découverte, 1987.

DE MASI, Domenico. A Sociedade Pós-Industrial. São Paulo: Editora do Senac, 1999.

DE SOUZA SANTOS, Boaventura. Pela mão de Alice. São Paulo: Cortez Editora, 1999.

FEYERABEND, Paul K. Cómo defender la sociedad contra la ciencia. In: HACKING, IAN (Org.). Revoluciones científicas. México: FCE, 1985.

Ética como medida de la verdad científica. In: TOMEO, Ana Maria (Org.). Feyerabend y algunas metodologías de la investigación. Montevideu: Nordan, 1991.
Matando o tempo, uma autobiografia. Editora Unesp: São Paulo, 1996.

GIDDENS, Anthony. A constituição da sociedade. São Paulo: Martins Fontes, 1989.

. As conseqüências da modernidade. São Paulo: Unesp, 1991.

1997.

et al. Modernização reflexiva. São Paulo: Unesp,

; TURNER, Jonathan H. Introdução. In: Teoria Social Hoje, p. 7-21. São Paulo: Editora Unesp, 1999.

HEISENBERG, Werner. A parte e o todo. Rio de Janeiro: Contraponto, 1996.

HORGAN, John. O fim da ciência: uma discussão sobre os limites do conhecimento científico. São Paulo: Companhia das Letras, 1998.

HORTON, Robin. La pensée traditionnelle africaine et la Science occidentale. In: La Pensée Métisse. PUF- Genebra: Cahiers de l'IUED, p. 45-67, 1990.

LATOUR, Bruno. Ciência em ação - como seguir cientistas e engenheiros sociedade afora. São Paulo: Unesp, 2000.

LEFF, Enrique. Sociología y ambiente: formación socioeconómica, racionalidad ambiental y transformaciones del conocimiento. In: LEFF, Enrique (Org.). Ciencias Sociales y Formación Ambiental. Barcelona: Gedisa Editorial, p. 17-84, 1994.

Saber ambiental: sustentabilidad, racionalidad, complejidad, Poder. México: Siglo XXI, 1998.

MARX, Karl; ENGELS, Fredrich. Miseria de la Filosofía. Buenos Aires: Editorial Cartago, 1973. 
FLORIANI, D. Diálogos interdisciplinares para uma agenda socioambiental:

MORIN, Edgar. La méthode - 4. Les idées. Paris: Éditions du Seuil, 1991.

. La complexité humaine. Paris: Flammarion, 1994.

PIGLIA, Ricardo. Entrevista con Ricardo Piglia. Fernando Fagnani, 19.3.2000.

PRIGOGINE, Ilya . O fim das certezas. São Paulo: Editora Unesp, 1996.
. Carta para as futuras gerações. Folha de São Paulo, São Paulo, 30 de jan. 2000. Caderno Mais!

STEIN, Ernildo. Epistemologia e crítica da modernidade. Rio Grande do Sul: Editora Unijuí, 1997.

TOURAINE, Alain. Crítica da modernidade. Petrópolis: Editora Vozes, 1994.

WEBER, Max. Ciência e Política, duas vocações. São Paulo: Cultrix, 1968. 